\title{
ARGUMENTOS PARA UMA HUMANIZAÇÃO DO ENSINO DAS CIÊNCIAS
}

\section{Arguments towards a humanization of science}

Paulo Maurício $^{1}$ • Bianor Valente ${ }^{1}$

Resumo: Identificando a rutura no desenvolvimento da ciência entre o contexto de descoberta e o contexto de justificação, julgamos poder entender melhor a dominação do ensino transmissivo da ciência em contexto escolar e melhor argumentar para a sua superação. Por outro lado, o argumento que aqui defendemos para recuperar, para o contexto de sala de aula, a fortíssima chama cultural que a ciência transporta nos seus conceitos, leis e teorias, bem como no seu próprio processo de desenvolvimento, tem uma tradição enraizada na cultura portuguesa que exploramos.

Palavras chave: Ensino de ciências. História. Filosofia. Ensino. Cultura.

\begin{abstract}
By identifying the rupture in the development of science between the context of discovery and the context of justification, we believe can better understand the domination of transmissive teaching of science in schools and argue for overcoming it. The argument is to recover for the classroom the very strong cultural flame that science carries in its concepts, laws and theories as well as in its own developmental processes. We explore the tradition rooted in Portuguese culture.
\end{abstract}

Keywords: Science education. History. Philosophy. Teaching. Culture.

\footnotetext{
${ }^{1}$ Escola Superior de Educação de Lisboa, Instituto Politécnico de Lisboa, ESELx, Campus de Benfica do IPL, 1549-003 Lisboa, Portugal. E-mail: paulom@eselx.ipl.pt
} 
Maurício, P.; Valente, B.

\section{Introdução}

Em 1809, na sua obra As afinidades electivas, Goethe capta um ambiente cultural em que a química ocupa um espaço crescente nas mentes e no tempo de lazer do público culto europeu (KIM, 2003, p. 2). Mas como entender as afinidades electivas como trama central do romance se a nossa memória histórica não lhe reserva espaço na revolução química dos finais do século XVII? Lavoisier, no seu Traité élémentaire de chimie, não dedica atenção particular ao tema das afinidades, ao contrário de muitos outros autores, como o português Vicente Seabra Telles (1764-1804), que elaborou, um ano antes do Traité élémentaire, o primeiro livro de texto de química em português com o intuito de ensinar a nova química aos estudantes da Universidade de Coimbra (CARNEIRO; DIOGO; SIMÕES, 2006). Deparamo-nos, deste modo, com uma rutura entre a nossa memória histórica e a memória cultural (ASSMANN; CZAPLICKA, 1995) que o livro de Goethe desencadeia em nós (KIM, 2003).

Pensamos que esta rutura identificada por Kim (2003) é parte de uma rutura mais vasta, parcialmente identificada no trabalho que temos vindo a referir, mas que podemos encontrar de modo igualmente belo no livro de Gould (2004): por um lado, entre as humanidades e a ciência, e, por outro, no interior da ciência, entre a ciência praticada pelos filósofos naturais (posteriormente, cientistas), a traduzida em livros de texto, e a ensinada nas universidades. Esta rutura entre a ciência tal como é realizada e a ciência tal como é ensinada é uma rutura intrínseca à ciência, enquanto a primeira é essencialmente de natureza social e resultou do trabalho de parto do nascimento da ciência.

Estas múltiplas fraturas foram muito provavelmente inevitáveis e, mesmo, necessárias. A Ciência teve de encontrar os seus espaços de desenvolvimento nos vários domínios teórico, institucional e político, que já não cabiam, de um modo geral, numa atividade de busca simultânea de explicações para os fenómenos naturais e de justificação filosófica da atividade desenvolvida: separação do contexto de justificação do contexto de descoberta. O que afirmamos não significa que, durante os dois séculos precedentes, não tivessem existido sempre cientistas que fizeram filosofia. Aliás, a ligação não poderia ser, de forma alguma, completamente quebrada: como afirma Matthews (2011, p. 4), a "ciência levanta questões filosóficas e exige compromissos filosóficos: ciência e filosofia caminham lado a lado"; e continuando, elenca uma pequena lista de cientistas, alguns dos quais se tornaram filósofos profissionais, ou tomaram a filosofia como a sua atividade central - Boltzmann, Planck, Bohr, Bunge, Holton, Polanyi, Bernal, Wilson e Gould.

Se olharmos para esta lista, identificamos pessoas que tomamos como historiadores da ciência, como seria o caso de John Bernal. Mas Gerald Holton, que segundo muitos é um físico que se tornou historiador da ciência, é para outros autores ${ }^{2}$ um filósofo, sendo mesmo um erro significativo considerá-lo historiador. Esta fluidez que verificamos existir, ao tentarmos uma classificação dos autores referidos, conduz-nos a uma primeira tese: a história e filosofia da ciência são duas áreas de conhecimento distintas mas intimamente ligadas. Lakatos (1998, p. 21) parafraseia a máxima de Kant: "A filosofia da ciência sem a história da ciência é vazia;

${ }^{2}$ Comunicação pessoal fornecida por Olga Pombo em 2011. 
Argumentos para uma humanização do ensino ...

a história da ciência sem a filosofia da ciência é cega." Para iniciar, uma discussão da sua filosofia, onde os "programas de investigação" substituem os paradigmas kuhnianos e o falsificacionismo de Popper. Esta ligação poderá ser também ilustrada com $A$ estrutura das revoluçôes científicas de Thomas Kuhn, obra de vasta e duradoura influência na historiografia da ciência, que foi publicada, pela primeira vez, não num projeto historiográfico, mas, sim, na International Encyclopedia of Unified Science de Otto Neurath, projeto filosófico resultante do Círculo de Viena que trabalhava no âmbito da unificação da ciência (POMBO, 2006).

\section{Origens da ciência nos currículos escolares: origem de problemas}

Podemos, agora, abordar o ensino-aprendizagem da ciência tal como foi desenvolvido no início do século XX. As orientações curriculares dirigiram-se para a formação de profissionais da ciência. Como exemplo, os alunos tinham de ser treinados na termodinâmica para alimentar o fluxo de cientistas e engenheiros que procuravam aumentar a eficiência das máquinas térmicas; em Química, para alimentar a florescente indústria química; em Geologia, para que não faltasse mão de obra para prosseguir o levantamento geológico dos Estados coloniais etc. Os Estados viram, no mais visível produto social da atividade cientifica, a tecnologia, uma força que usaram para se afirmar económica, social e politicamente. A organização da atividade científica, ou organização da ciência, para simplificar, foi tarefa do Estado: universidades, laboratórios, grandes centros de investigação proliferaram como centros de onde irradiava o saber e o poder (PESTRE, 1997; SIMÕES 2011), e que tinham de ser alimentados com cientistas, engenheiros e outros técnicos. A Bomba não foi feita por meia dúzia de génios, mas por muitas centenas de cientistas e técnicos, numa organização quase militar da ciência. Como é referido no relatório da Nuffield Foundation (OSBORNE; DILLON, 2008, p. 7, grifos nossos, tradução nossa), "Muito da actual preocupação sobre educação em ciência [...] concentra-se apenas na provisão de futuros cientistas e engenheiros [...]". O relatório prossegue afirmando que

O problema com o enquadrar a discussão sobre a ciência escolar em termos do suprimento da próxima geração de cientistas, é que ela define o principal objetivo da educação em ciência como um pipeline [...]. Ao fazê-lo coloca uma responsabilidade sobre a educação em ciência na escola que nenhum outro currículo partilha. (ORBORNE; DILLON, 2008, p. 7, grifo nosso, tradução nossa)

A mesma justificação para a entrada da ciência nos currículos surge no relatório de Fensham (2008) para a UNESCO: facilitar a passagem "para uma pequena elite" dos estudantes de ciências do ensino secundário para a universidade "para que se tornassem a próxima geração de cientistas, engenheiros e médicos" (p. 14-15, tradução nossa). A extensão do ensino da ciência aos primeiros anos de ensino, ainda segundo Fensham (2008), não levou a mudanças nos seus propósitos originais. De facto 
Maurício, P.; Valente, B.

Ao reformular os curricula para incluir a ciência e a tecnologia, o conteúdo da aprendizagem [...] ainda levava o forte tom concetual que caracterizou a preparação em ciência do grupo de elite quando eles eram a única preocupação e propósito do ensino escolar. (FENSHAM, 2008, p. 15, tradução nossa)

Assim, as raízes do ensino tradicional da ciência são bem fundas na nossa história e têm ramificações nos domínios e/ou aos níveis do professor, da escola, da comunidade, da política curricular e das políticas educativas.

Rutherford (2001) diz que os curricula estão delimitados pela tradição: as elites de cada geração de adultos acredita que o ensino deve ser muito semelhante ao que eles próprios vivenciaram. Höttecke e Silva (2011) enquadram a persistência do ensino tradicional numa "cultura disciplinar", que definem como compreendendo

[...] o conjunto das características de uma disciplina como processos e métodos de ensino e aprendizagem, estratégias instrucionais, conteúdo visto como obrigatório ou adicionado ao obrigatório, bem como expetativas, hábitos aceites ou rejeitados e ênfases curriculares dos seus membros. (HÖTTECKE; SILVA, 2011, p. 4, tradução nossa)

Um professor imerso numa cultura disciplinar determinada participa "numa prática socialmente partilhada de objetivos, conteúdo relevante, e projetos instrucionais." (HÖTTECKE; SILVA, 2011, p. 4, tradução nossa). O professor de Física define como seu principal objetivo o de transmitir a verdade, segundo estudos reportados em Höttecke e Silva (2011). Enquanto numa aula de inglês as opiniões dos alunos contam, diferentes opiniões são vistas como menos importantes numa aula de Física. Ora, os alunos confrontam as disciplinas num ritmo diário, saindo de uma aula onde as suas opiniões e expressões são valorizadas para uma outra onde não há diferentes opiniões: Os professores de Física "não percebem o conteúdo como matéria de discussão e negociação entre os seus alunos. Logo, memorizar factos científicos é um importante aspeto do ensino da física" (HÖTTECKE; SILVA, 2011, p. 4, tradução nossa).

Num outro relatório promovido pela Nuffield Foundation (OSBORNE; DUSCHL; FAIRBROTHER, 2002, p. 30-31, tradução nossa), a resistência à mudança por parte do professor é evidenciada, sendo "difícil escapar à sensação que parte da razão para o domínio do conteúdo [no ensino] da ciência é que esta atividade - explicar ciência - é um território familiar para muitos professores, no qual se sentem à vontade e que fluentemente desenvolvem [...]" sempre que uma ocasião surge. Em conclusão, podemos remeter para o trabalho de Chagas (2000, p. 9) onde "numerosos estudos e relatórios têm vindo a confirmar uma tendência generalizada a nível internacional para a conservação de práticas que reforçam o ensino convencional da ciência centrado na aquisição de terminologia, factos, princípios e leis [...]."

O professor surge, então, como um elemento central no processo de ensinoaprendizagem, e, logo, um ator importante nos processos de mudança ou, como vimos, nos processos de resistência à mudança. Mas, acima, identificámos as raízes do ensino tradicional da ciência como fundadas não apenas no professor, mas, também, na escola, na comunidade, no currículo e nas políticas educativas. De facto, alguns dos trabalhos que referimos 
Argumentos para uma humanização do ensino ...

(HÖTTECKE; SILVA, 2011; OSBORNE; DUSCHL; FAIRBROTHER, 2002) identificam estes variados atores, ou alguns deles e em matizes diversas, e o seu papel na manutenção/ transformação do processo de ensino-aprendizagem. Como exemplo adicional, Chagas (2000, p. 9-10) afirma que mudar implica "mudar muitas vertentes": curricula, avaliação, recursos, formação e, por fim, a Escola "cuja cultura pode facilitar ou impedir qualquer tentativa de mudança". Kahle (2007, p. 913-922, tradução nossa), ao discutir reformas sistémicas em larga escala, mostra que "a primeira onda [referindo-se ás várias ondas de reforma educacional pósSputnik] de reforma da educação em ciência não se dirigiu a todas as partes do sistema", mas focou-se no aumento da qualificação dos professores e nos livros de texto. Como refere Kahle (2007, p. 922), "ambos os esforços mudaram a educação em ciência de forma substancial, e a sinergia entre os dois focos [de mudança sistémica] aumentou os seus efeitos separados".

No fim, questões e preocupações do domínio político limitaram as reformas educacionais das décadas de 1960 e 1970, "apesar de elas refletirem uma visão partilhada de uma melhor educação em ciência” (KAHLE, 2007, p. 922, tradução nossa).

\section{Ultrapassar o problema}

A educação em ciência tem procurado - certamente desde as reformas educacionais pós-Sputnik, desencadeadas nos EUA, mas com evidências relevantes de tentativas anteriores (AIKENHED, 2007; HOLTON, 2003a; HOLTON, 2003b; SEQUEIRA; LEITE, 1988; SEROGLOU; KOUMARAS, 2001) - transformar o ensino da ciência de um ensino transmissivo, centrado no professor e com o foco nos conteúdos científicos, para um ensino centrado no aluno, contextualizado, baseado no inquiry, e no qual se aprenda sobre a natureza da ciência e se entendam controvérsias sócio-científicas (AIKENHEAD, 2007; CHAGAS, 2000; EUROPEAN COMMISSION, 2007).

Como é vasta a literatura onde é racionalizado um ensino-aprendizagem da ciência onde os conteúdos metacientíficos estão presentes (LEDERMAN, 2007; MATTHEWS, 1992; WANG; MARSH, 2002), a terminologia é, naturalmente, muito diversa para referir este processo: ensino de ciência em contexto (ou contextualizado), ensino da ciência com uma vertente humanista, ensino da ciência com História e Filosofia da Ciência, ensino da ciência e da natureza da ciência etc.

Para clarificação de termos, usaremos a expressão ensino da ciência com HFC e, ao ensino centrado no aluno, contextualizado, baseado no inquiry e no qual se aprenda sobre a natureza da ciência e se entendam e discutam controvérsias sócio-científicas, denominaremos um ensino humanizado, já usado na literatura (AIKENHEAD, 2007).

\section{Humanização do ensino da ciência: reflexão no contexto cultural português}

Com raízes na tradição cultural portuguesa, existem alguns pensadores que problematizaram o ensino humanizado da ciência e o ensino com HFC. Vitorino Magalhães Godinho (1918-2011) afirma que "para compreender o processo do conhecimento importa 
ter em conta a evolução da ciência como desenvolvimento de ideias e como parte do conjunto das relações humanas" (GODINHO, 1971a, p. 224). E um pouco mais à frente acrescenta

É útil, afigura-se-me, iluminar a mútua conexão da ciência, da filosofia e da história da ciência: de uma filosofia que não seja escolástica estéril ou retórica desordenada, de uma história da ciência que veja as ideias e não as datas, de uma ciência viva e profundamente bumana. (GODINHO, 1971a, p. 224, grifo nosso)

Vemos, em Godinho (1971b), uma preocupação profunda com o estado do ensino em Portugal, mas, em particular, com uma ênfase interessante na HFC: "a História da Ciência e do pensamento científico não merece qualquer atenção nos curricula oficiais, secundários ou ditos superiores" (GODINHO, 1971b, p. xxiii).

Já António Sérgio (1888-1969) apela ao abandono da pedagogia que classifica de dogmática, desumana e passiva. Dogmática, diz Sérgio (2006, p. 93), "por não apresentar com clareza aos jovens o motivo por que se adoptou a concepção ensinada, quer dizer: como se chegou até ela". Desumana "por não mostrar o esforço mental do cientista, o sacrifício, a canseira, a abnegação, a energia, a luta a que se sujeita para que se aceite a sua verdade" (SÉRGIO, 2006, p. 93). Passiva, "porque não revela aos alunos como se constrói a doutrina, isto é, porque não busca apontar-lhes o trabalho inventivo, a fantasia criadora de onde o saber promana. Porque diz que se descobre, e não que se cria a ciência" (SÉRGIO, 2006, p. 93, grifo do autor). Além do mais, como afirma o autor, o progresso "exigiu sempre a polémica" necessária para combater o dogmatismo sempre à espreita, pelo que

conviria $[. .$.$] combater o dogmatismo com delinear a história, ao menos,$ das mais célebres e importantes entre as concepções dos sábios, ligandoas às exigências do trabalho humano, quando por elas surgiram; ademais caracterizar as fases da investigação metódica, salientando o papel da congeminação criadora, - dessa livre fantasia de onde brota a hipótese; e apresentar a ciência na sua realidade humana [...] jamais separando o saber científico da atividade-do-espírito que o vai criando. (SÉRGIO, 2006, p. 94-95)

Armando de Castro (1918-1989) autor da monumental obra Teoria do conbecimento científico, de que estão publicados, ainda que fora de edição, 8 volumes, no seguimento do pensamento marxista português, denuncia "As tendências utilitárias, pragmáticas [...] evidentes no ensino médio e superior do nosso país" (CASTRO, 1988, p. 235), acrescentando, de seguida, que "um dos meios de a combater no plano pedagógico consiste em aliar o ensino teórico e prático ao ensino [...] através da história crítica de cada disciplina". E sublinha que

no próprio plano educativo um ensino das ciências a-histórico, como sublinhava já então Paul Langevin, perde interesse para os estudantes que o procuram adquirir, tornando-se frio, estático, e levando à convicção de que a ciência é uma atividade morta, um conjunto de 
Argumentos para uma humanização do ensino ...

posições definitivas e insuperáveis. [Essa apresentação a-histórica], além de mecanizar uma atividade que, pela sua própria natureza deve ser criadora, introduz distorções na compreensão de diversas teorias científicas. (CASTRO, 1988, p. 235-236)

Armando de Castro (1988, p. 233) adianta que “[...] distinguir a atividade ideológica [ou pré-científica] ou a atividade filosófica da atividade científica é uma tarefa fundamental, quer nas ciências do homem [por razões que apontou anteriormente] quer inclusive nas ciências do mundo inorgânico e biológico".

Também nesta tarefa a "história das ciências não se pode pôr de lado, pois ministra ensinamentos válidos ao apontar para as repetidas intromissões de um e de outro plano no 'saber científico'; deste modo, [a história da ciência] participa activamente no esforço de purificar estes diversos planos" (CASTRO, 1988, p. 233).

Importa determo-nos um pouco nesta reflexão. Veja-se como, para Armando de Castro, a atividade científica não está isenta de "contaminações" vindas tanto do conhecimento comum, não científico - apontando assim para uma dimensão pessoal da atividade científica que encontramos nos themata da epistemologia de Holton (crenças muito pessoais que 'dirigem' as escolhas que o cientista tem de realizar), mas, também, "contaminações" eminentemente sociais na construção do conhecimento científico, pois o "conhecimento comum" é, também, um conhecimento social, ou socialmente partilhado. De facto, Castro (1988, p. 232, grifo nosso) explicita esta ideia ao defender que a "formulação de problemas científicos nasce da lógica interna do desenvolvimento disciplinar combinada com as exigências do meio social em que esta problemática surge".

É necessário colocarmos estas problematizações no contexto de um país periférico e com quarenta anos de ditadura fascista, e onde a influência predominante nos meios intelectuais, tanto progressistas como conservadores, era a cultura francófona. No entanto, como veremos, é do meio anglófono que provêm as principais - as mais férteis, sem dúvida - forças motrizes de mudança curricular para um ensino humanista. Mas estes condicionantes não devem conduzir-nos a uma acção irrefletida de desvalorização destes contributos.

Profundamente inseridos na realidade portuguesa, estes apelos a um ensino da ciência humanizado (de alcance curricular certamente quase nulo) merecem ser objecto de investigação. Nomeadamente as propostas teóricas avançadas, com eventual utilidade para a epistemologia das ciências da educação (aqui, parece-nos que Armando de Castro e Magalhães Godinho terão contribuições significativas); as propostas teóricas avançadas para a integração da HFC no ensino da ciência - como, por um lado, se inserem e, por outro, se distinguem, no e do contexto português, e, por fim, propostas didácticas relevantes, onde talvez António Sérgio tenha aqui um papel mais significativo.

\section{Humanização do ensino da ciência: reflexão com influência curricular}

A humanização do ensino da ciência constitui-se como a "mais generalizada" fonte de geração de propostas curriculares alternativas ao ensino tradicional da ciência, com o objetivo de preparar cidadãos que, de modo racional e crítico, vivam a sociedade imersa na ciência e 
pela ciência e tecnologia (AIKENHEAD, 2007, p. 881). Solbes e Traver (2003, p. 704), após uma descrição e breve análise das causas prováveis da crise que o ensino da ciência atravessa, avançam com a exposição de duas linhas de propostas curriculares, com o intuito preciso de "evitar a crise actual da educação em ciência". Uma, remontando a Conant, prosseguindo com Holton e com o Project Physics Course, e reforçada com a contribuição de Schwab e das propostas oriundas da Biological Science Curriculum Study (BSCS), defenderia a introdução da HFC, mas estaria mais ligada à história interna da ciência (SOLBES; TRAVER, 2003). Outra, ligada aos movimentos CTS, colocaria a ênfase na história externa da ciência.

Aikenhead (2007, p. 884), por sua vez, enquadra as propostas CTS como resultantes tanto da "interacção da ciência e dos cientistas com questões sociais e institucionais externas à comunidade científica", como da "interacção dos cientistas e dos seus valores comunitários, epistémicos e ontológicos internos à comunidade científica" (AIKENHEAD, 2007, p. 884, grifo do autor).

De facto, dos problemas levantados pela Big Science que surgiram numa janela temporal relativamente larga (relação Estado-Ciência; Bomba atómica, chuvas ácidas, questões energéticas e ambientais, como energias renováveis, escassez de recursos e aquecimento global), foram poucos ou quase nenhuns os que motivaram as primeiras propostas curriculares para um ensino humanizado. A preocupação de Conant em que cada cidadão compreenda o que denominou de "táctica e estratégia da ciência" (HOLTON, 2003b, p. 612) liga-se à sua motivação de tom muito conservador, pela coesão social da América e "preservação da nossa civilização". Seria dos fins da década de 1960 até a década de 1980 que o eclodir dos movimentos ecologistas e pacifistas, por exemplo, deram expressão pública a uma realidade que já vinha percorrendo a atividade científica: a ligação CTS.

Assim, seríamos tentados a ver, na divisão de Solbes e Traver (2003), uma proposta heurística útil, caso não víssemos que as preocupações de Conant são, em todos os aspetos relevantes, preocupações CTS: preocupações com a influência da ciência na sociedade e desta na ciência; preocupações sobre a "sobrevivência da nossa civilização": bomba atómica, questões éticas e morais etc.

Deste modo, não vislumbramos a necessidade de sustentar as propostas CTS num outro quadro concetual diferente daquele que levou ao emergir do Project Physics Course. Mas a ênfase, essa sim, foi mudando; os slogans foram-se alterando. Desde a década de 1970, que a perspectiva humanista do ensino das ciências tem sido identificada com os curricula CTS (AIKENHEAD, 2007, p. 882).

Ora, ainda que seja esmagadora a evidência sobre o fracasso educacional do ensino tradicional em ciência (AIKENHEAD, 2007; SOLBES; TRAVER, 2003), a resistência à mudança é enorme (AIKENHEAD, 2007, CHAGAS, 2000; CHUBIN, 2000). Como Chubin (2000, p. 259) afirma no seu artigo intitulado Reculturing Science, que foi buscar a "muito ouvida frase" reinventing governement, "como muitas exortações, esta passa pelos lábios sem demasiado esforço. Fazer ocorrer mudanças é outra coisa. Mas elas devem acontecer. [...] [os hábitos], no entanto, são muito difíceis de quebrar.". Podíamos, aqui, parafrasear Bachelard e desconfiar, com ele, do que se concretiza sem esforço; do que é fácil.

A investigação realizada sobre a transformação do ensino tradicional, educacionalmente um fracasso, mas com elevado estatuto entre os professores (AIKENHEAD, 2007; EUROPEAN COMMISSION, 2007), leva-nos a considerar a categoria de relevância curricular. 
Argumentos para uma humanização do ensino ...

Aikenhead (2007) analisa a relevância olhando para "quem decide" e adopta sete categorias. "Ciência como cultura" surge como uma categoria de relevância mais global, capaz de servir de chapéu às outras categorias, e, de modo a sustentarmos um ensino com HFC, é aquela que nos surge como particularmente importante como suporte da disseminação da ciência.

Na construção de Popper (1978), dos Três Mundos, os produtos, processos e ideias da ciência ocupam o mesmo mundo do que na linguagem comum designamos como produtos culturais. "Exemplos de objectos do mundo 3 são: a Constituição Americana; ou The Tempest de Sheakespeare; ou o seu Hamlet; ou a Quinta sinfonia de Beethoven; ou a teoria da gravitação de Newton" (POPPER, 1978, p. 145), sendo que estes objetos que habitam o Mundo 3 "tais como teorias jogam um papel tremendo na mudança do mundo 1" (POPPER, 1978, p. 164). Já para Fischer e Mandell (2009, p. 35), referindo o conhecimento tácito de Michael Polanyi,

as várias tradições e convenções que influenciam e por vezes conduzem as interacções sociais inerentes ao inquérito científico não são imediatamente visíveis. [...] [Polanyi] identificou um processo de conhecimento tácito [...] como um reportório de conhecimentos e crenças que perpassa 'a procura tradicional do inquérito científico', constituindo o próprio sustentáculo do qual o conhecimento objetivo adquire tanto a sua possibilidade como o seu significado.

Nestas influências não visíveis podemos vislumbrar as influências culturais pessoais e comunitárias. Também em Holton $(1973,1978)$, a terceira dimensão thematica possui uma forte determinação cultural, ainda que, no seu trabalho, tivesse sempre evitado explicitar as origens dos themata.

O autor, no entanto, avança de modo mais audacioso na problematização da ciência como cultura e analisa a questão sob outro ângulo. Num seu ensaio, inicialmente escrito em 1963 e significativamente intitulado Physics and culture: criteria for curricula design, Holton (1973, p. 463-464, grifo nosso) afirma que

as muito discutidas clivagens no conhecimento [entre ciência e cultura] são demasiadas vezes o resultado de definições erróneas. A controvérsia entre T. S. Eliot e os seus críticos, ou, mais recentemente, entre Snow e Leavis, serve para nos lembrar o quão necessário é, para cada geração, repensar o que é 'cultura' nos seus múltiplos sentidos, o que faz a adesão de um povo a uma cultura, e que forças e mecanismos actuam na sua transformação. A esta luz o tópico importante não é até que ponto a ciência é uma atividade separada de outras, mas antes como podemos definir e transmitir a cultura de tal modo que a ciência seja vista como uma componente válida da nossa cultura.

Em José António Marina (1995, p. 71), encontramos uma bela descrição dos "propósitos" da ciência. Esta, a ciência, "propõe-se esclarecer as coisas, e esclarecê-las significa deixar que se perceba a sua bela luminosidade". Adiantando ainda que 
Maurício, P.; Valente, B.

O astrónomo não deve cantar as glórias da criação, antes buscar as leis que regem o girar dos astros, mas não seria de mais que comunicasse, ao mesmo tempo que a fórmula, a exaltação que produziu nele o conhecimento da exacta, límpida e precisa música das esferas celestiais. (MARINA, 1995, p. 71)

O espanto perante uma obra de Fauré, um livro de José Cardoso Pires, ou uma pintura de Malevich não é diferente da exaltação referida por António Marina (1995).

Uma concetualização de ciência como uma cultura (science as a culture, no original), claramente inspirada na teoria dos programas de investigação de Lakatos (1998), é desenvolvida por Galili (2012). O foco da abordagem de Galili (2012) são os próprios conteúdos científicos, alvos de "apertado escrutínio pelo discurso disciplinar", e é fundamentado nas abordagens que relevam a pluralidade concetual no entendimento dos conceitos - como, por exemplo, as várias abordagens à Relatividade Geral geradas por diferentes concepções do "espaço" (LEVRINI, 2002, p. 275) - bem como na natureza discursiva do conhecimento disciplinar (GALILI, 2012).

Por fim, Gould (2004) é peremptório em defender que, embora o "suposto" conflito entre a ciência e a religião tenha merecido mais destaque, ele é tão antigo e profundo como aquele que contesta as interacções da ciência com as artes e as humanidades. Assim, afirma que

por mais logicamente sólidas e por mais sancionadas por uma longa persistência histórica [que surjam], as nossas taxonomias das disciplinas humanas surgem por razões largamente arbitrárias e contingentes de normas sociais e práticas universitárias passadas, assim criando falsas barreiras [...] Por exemplo, sinto que fiz os meus principais avanços no meu próprio campo da paleontologia apenas quando [...] explicitamente compreendi que as ferramentas necessárias para compreender muito dos padrões da evolução residiam em metodologias estabelecidas por historiadores em departamentos das nossas faculdades de humanidades. (GOULD, 2004, p. 17-18)

\section{Conclusão}

Ainda que o ensino tradicional da ciência de aspeto essencialmente transmissivo e não problemático, culturalmente desenraizado e não fornecedor de contexto para os alunos, seja dominante no ensino, pensamos que, para um desenvolvimento efetivo no contexto português, a análise de propostas teóricas com repercussões curriculares avançadas nos EUA e GB de humanização da ciência ganham com uma recontextualização na tradição cultural portuguesa. Tal recontextualização resultará de um trabalho de Transposição Didática (CHEVALLARD, 1991) onde o conhecimento sábio é trabalhado pelo professor em conhecimento a ensinar. Os critérios de seleção, e os trabalhos de transformação e de apropriação do conhecimento sábio em conhecimento a ensinar tornam-se mais férteis se virmos o saber

1022

Ciênc. Educ., Bauru, v. 19, n. 4, p. 1013-1026, 2013 
Argumentos para uma humanização do ensino ...

disciplinar (saber sábio) como um cultura disciplinar (TSEITLIN; GALILI, 2005) onde é possível uma apropriação dialógica.

Os estudos de caso produzidos no âmbito do projeto de investigação History and philosophy in science teaching (HÖTTECKE, 2012) constituem-se como um importante passo no caminho de transformação do ensino da ciência. Ao se desvendar e explorar a riqueza das formulações teóricas no próprio processo da sua criação, atinge-se outra compreensão das dificuldades atuais no ensino-aprendizagem de alguns conteúdos escolares, como os conceitos de força ou de energia (COELHO, 2009). Por outro lado, ao se concretizarem as conexões de natureza disciplinar propostas na epistemologia de Holton, o saber sábio não é trabalhado num gueto, mas num ambiente de diálogo com as humanidades.

\section{Referências}

AIKENHEAD, G. S. Humanistic perspectives in the science curricula. In: ABELL, S. K.; N. G.; LEDERMAN, N. G. (Ed.). Handbook of research in science education. New York: Routledge, 2007. p. 881-910.

ASSMANN, J.; CZAPLICKA, J. Collective memory and cultural identity. New German Critique, Durham, n. 65, p. 125-133, 1995. Disponível em: <http://www.jstor.org/stable/ 488538? origin $=$ JSTOR-pdf > . Acesso em: 21 out. 2013.

CARNEIRO, A.; DIOGO, A. P.; SIMÕES, A. Communicating the new chemistry in 18th-century Portugal: Seabra's Elementos de Cbimica. Science \& Education, Dordrecht, v. 15, n. 7-8, p. 671-692, 2006. Disponível em: <http://dx.doi.org/10.1007/s11191-0058630-5>. Acesso em: 21 out. 2013.

CASTRO, A. Textos didáticos. In: (Org.). Conhecer o conhecimento. Lisboa: Caminho, 1988. p. 213-241.

CHAGAS, I. Literacia cientifica: o grande desafio para a escola. In: ENCONTRO NACIONAL DE INVESTIGAÇÃO E FORMAÇÃO, GLOBALIZAÇÃO E DESENVOLVIMENTO PROFISSIONAL DO PROFESSOR, 1., 2000, Lisboa. Actas... Lisboa: ESELx, 2000. Disponível em: <http://www.educ.fc.ul.pt/docentes/ichagas/ticc/ literacia\%20cientifica.pdf >. Acesso em: 21 out. 2013.

CHEVALLARD, Y. La transposition didactique du savoir savant au savoir enseigné. Grenoble: La Pensée Sauvage, 1991.

CHUBIN, D. E. Reculturing science: politics, policy, and promises to keep. In: KUMAR, D. D.; CHUBIN, D. E. (Ed.). Science, technology and society: a sourcebook on research and practice. New York: Kluwer: Plenum, 2000. p. 257-276.

COELHO, R. L. On the concept of energy: how understanding its history can improve physics teaching. Science \& Education, Dordrecht, v. 18, n. 8, p. 961-983, 2009.

Disponível em: <http://dx.doi.org/ 10.1007/s11191-007-9128-0>. Acesso em: 21 out. 2013. 
Maurício, P.; Valente, B.

EUROPEAN COMMISSION. Science education now: a renewed pedagogy for the future of Europe. Brussels, 2007. Disponível em: <http://ec.europa.eu/research/sciencesociety/document_library/pdf_06/report-rocard-on-science-education_en.pdf $>$. Acesso em: 17 out. 2013.

FENSHAM, P. J. Science education policy-making: eleven emerging issues. [S. 1.]: UNESCO, 2008. Disponível em: < http://unesdoc.unesco.org/images/0015/001567/ 156700e.pdf >. Acesso em: 17 out. 2013.

FISCHER, F.; MANDELL, A. Michael Polanyi's republic of science: the tacit dimension. Science as Culture, Abingdon, v. 18, n. 1, p. 23-46, 2009. Disponível em: <http:/ / dx.doi.org/10.1080/09505430802705889>. Acesso em: 21 out. 2013.

GALILI, I. Promotion of cultural content knowledge through the use of the history and philosophy of science. Science \& Education, Dordrecht, v. 21, n. 9, p. 1283-1316, 2012. Disponível em: <http://dx.doi.org/10.1007/s11191-011-9376-x>. Acesso em: 21 out. 2013.

GODINHO, V. M. Prefácio. In: ENSAIOS: humanismo científico e reflexão filosófica. Lisboa: Sá da Costa, 1971b. v. 4, p. i-xxix.

. O significado da história do pensamento científico. In: ENSAIOS: humanismo científico e reflexão filosófica. Lisboa: Sá da Costa, 1971a. v. 4, p. 221-225.

GOULD, S. J. The hedghog, the fox, and the magister's pox: mending the gap between science and humanities. London: Vintage, 2004.

HOLTON, G. J. The project physics course, then and now. Science \& Education, Dordrecht, v. 12, n. 8, p. 779-786, 2003a. Disponível em: <http://dx.doi.org/10.1023/ B:SCED.0000004544.55635.40>. Acesso em: 21 out. 2013. 1978.

The scientific imagination: case studies. London: Cambridge University Press,

. Thematic origins of scientific thought: Kepler to Einstein. Cambridge:

Harvard University Press, 1973.

What historians of science and science educators can do for one another. Science \& Education, Dordrecht, v. 12 n. 7, p. 603-616, 2003b. Disponível em: <http:// dx.doi.org/10.1023/A:1025675922918>. Acesso em: 21 out. 2013.

HÖTTECKE, D. HIPST - History and philosophy in science teaching: a european project. Science \& Education, Dordrecht, v. 21, n. 9, p. 1229-1232, 2012. Disponível em: <http:/ /dx.doi.org/10.1007/s11191-011-9435-3>. Acesso em: 17 out. 2013.

HÖTTECKE, D.; SILVA, C. C. Why implementing history and philosophy in school science education is a challenge: an analysis of obstacles. Science $\boldsymbol{E}$ Education, Dordrecht, v. 20, n. 3-4, p. 293-316, 2011. Disponível em: <http://dx.doi.org/10.1007/ s11191-010-9285-4>. Acesso em: 17 out. 2013. 
Argumentos para uma humanização do ensino ...

KAHLE, J. B. Systemics reforms: research, vision, and politics. In: ABELL, S. K.;

LEDERMAN, N. G. (Ed.). Handbook of research on science education. New York: Routledge, 2007. p. 911-941.

KIM, M. G. Affinity, that elusive dream: a genealogy of the chemical revolution. Cambridge: MIT Press, 2003.

LAKATOS, I. História da ciência e suas reconstruções racionais: e outros ensaios. Lisboa: Edições 70, 1998.

LEDERMAN, N. G. Nature of science: past, present, and future. In: ABELL, S. K.; LEDERMAN, N. G. (Ed.). Handbook of research in science education. New York: Routledge, 2007. p. 831-879.

LEVRINI, O. Reconstructing the basic concepts of general relativity from an educational and cultural point of view. Science \& Education, Dordrecht, v. 11, n. 3, p. 263-278, 2002. Disponível em: <http://dx.doi.org/ 10.1023/A:1015297814508>. Acesso em: 22 out. 2013.

MARINA, J. A. Teoria da inteligência criadora. Lisboa: Caminho, 1995.

MATTHEWS, M. R. History, philosophy, and science teaching: the present rapprochement. Science \& Education, Dordrecht, v. 1, n. 1, p. 11-47, 1992. Disponível em: <http:// dx.doi.org/10.1007/BF00430208 >. Acesso em: 23 out. 2013.

Teaching the philosophical and worldview components of science. In:

KOKKOTAS, P. V.; MALAMITSA, K. S.; RIZAKI, A. A. Adapting historical knowledge production to the classroom. Rotterdam: Sense Publishers, 2011. p. 3-16.

OSBORNE, J.; DILLON, J. Science education in Europe: critical reflections. London: The Nuffield Foundation, 2008. Disponível em: < http://www.nuffieldfoundation.org/ sites/default/files/Sci_Ed_in_Europe_Report_Final.pdf>. Acesso em: 21 out. 2013.

OSBORNE, J.; DUSCHL, R.; FAIRBROTHER, R. Breaking the mould?: teaching science for public understanding . London: The Nuffield Foundation, 2002. Disponível em: $<$ http://nuffieldfoundation.org/sites/default/ files/

Breaking $\% 20$ the $\% 20$ mould_science $\% 20$ for $\% 20$ public $\% 20$ understanding.pdf $>$. Acesso em: 17 out. 2013.

PESTRE, D. Science, political power and the state. In: KRIGE, J.; PESTRE, D. (Ed.). Science in the twentieth century. Amsterdam: Harwood Academic, 1997. p. 61-75.

POMBO, O. Unidade da ciência: programas, figuras e metáforas. Lisboa: Duarte Reis, 2006.

POPPER, K. Three worlds: the Thanner lecture on human values delivered at The University of Michigan April 7, 1978. Disponível em: <http://www.thee-online.com/ Documents/Popper-3Worlds.pdf>. Acesso em: 21 out. 2013. 
Maurício, P.; Valente, B.

RUTHERFORD, F. J. Fostering the history of science in american science education.

Science \& Education, Dordrecht, v. 10, n. 6, p. 569-580, 2001. Disponível em: <http:// dx.doi.org/10.1023/A:101753322628>. Acesso em: 21 out. 2013.

SEQUEIRA, M.; LEITE, L. A história da ciência no ensino-aprendizagem das ciências. Revista Portuguesa de Educação, Braga, v. 1, n. 2, p. 29-40, 1988. Disponível em: $<$ http://repositorium.sdum.uminho.pt/bitstream/1822/436/1/1988,1(2),2940(ManuelSequeira\%2526LaurindaLeite).pdf>. Acesso em: 22 out.2013.

SÉRGIO, A. Cartas de problemática. In: POMBO, O.; REIS, M. B.; CORDOVIL, J. L. (Ed.). As cartas de problemática de António Sérgio. Lisboa: CFCUL, 2006. p. 29-124. (Cadernos de filosofia das ciências, 3).

SEROGLOU, F.; KOUMARAS, P. The contribution of the history of physics in physics education: a review. Science \& Education, Dordrecht, v. 10, n. 1-2, p. 153-172, 2001. Disponivel em: <http://dx.doi.org/ 10.1023/A:1008702000098 >. Acesso em: 22 out. 2013.

SIMÕES, A. Da revolução científica à Big Science. [S. 1.: s. n.], 2011. Disponível em: $<$ http://cosmo.fis.fc.ul.pt/ asimoes/aulas/RC_BigScience.pdf>. Acesso em: 21 out. 2013.

SOLBES, J.; TRAVER, M. Against a negative image of science: history of science and the teaching of physics and chemistry. Science \& Education, Dordrecht, v. 12, n. 7, p. 703717, 2003. Disponível em: <http://dx.doi.org/10.1023/A:1025660420721>. Acesso em: 21 out. 2013.

TSEITLIN, M.; GALILI, I. Physics teaching in the search for its self. Science \& Education, Dordrecht, v. 14, n. 3-5, p. 235-261, 2005. Disponível em: <http://dx.doi.org/ 10.1007/s11191-004-7943-0>. Acesso em: 21 out. 2013.

WANG, H. A.; MARSH,D. D. Science instruction with a humanistic twist: teachers' perception and practice in using the history of science in their classrooms. Science $\boldsymbol{\&}$ Education, Dordrecht, v. 11, n. 1, p. 169-189, 2002. Disponível em: <http://dx.doi.org/ 10.1023/A:1014455918130>. Acesso em: 21 out. 2013.

Artigo recebido em 03/02/13. Aceito em 09/11/13. 